\title{
The properties of doped sand-lime products
}

\author{
Ryszard Dachowski ${ }^{1}$, Katarzyna Komisarczyk ${ }^{2, a}$ \\ ${ }^{1}$ PhD. DSc, Kielce University of Technology, Department of Civil and Environmental Engineering, Al. 1000-Lecia P.P.7 Kielce, Poland \\ ${ }^{2} \mathrm{MSc}$, Kielce University of Technology, Department of Civil and Environmental Engineering, Al. 1000-Lecia P.P.7,25-317 Kielce, Poland
}

\begin{abstract}
Sand-lime products are natural materials consisting of lime, sand and water with the least content of radioactive elements in comparison to other masonry elements. They are characterized by very high compressive strength, high acoustic insulation, good thermal properties, provide a friendly atmosphere and prevent the spread of mold and bacterial flora. In addition they are fully recyclable. White bricks through the porous structure and the occurrence of capillaries have the ability to rising water. The height of capillary action is dependent on the contact angle and the size of existing pores in the material. This property affects the frost resistance and other characteristics of durability of wall materials operated under conditions of intense exposure to moisture. The aim of the study is to determine the impact modifier on the properties of autoclaved sand-lime products. For testing used

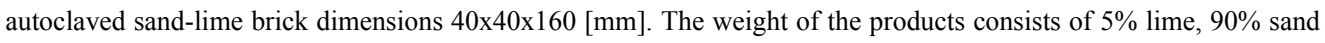
and $5 \%$ lithium water glass $(\mathrm{MP}=2,6$ and $\mathrm{MP}=7,0)$. The produced samples were subjected to autoclaving at temperatures of $203^{\circ} \mathrm{C}$ and pressure of $1.6 \mathrm{MPa}$ in collaboration with the Silicate Production Plant in Ludynia. Three finished sets of samples (standard, modified with lithium silicate 2.6 and 7.0) have been immersed in water to the desired height during certain time. The results show the diversity of the internal structure of the tested products. In particular pore distribution, size and volume.
\end{abstract}

\section{Introduction}

The economic development of the XXI century contributes to upsetting the balance in the environment. The way to prevent the negative effects of this development is the concept of sustainable development. It ensures meeting the needs of current generations without compromising the ability of future needs. Construction aimed at satisfying the basic needs of society is one of the key elements of sustainable development. The Directive Council of the European Communities [1] and polish building regulations need to ensure that products intended for use in buildings meet the criteria such as: mechanical resistance and stability, fire safety and utility, noise protection, energy saving and heat protection of buildings. For the construction of houses and flats suitable building materials are used. Their properties should take into account their impact on health, hygiene and environment.

Sand-lime products are natural materials consisting of lime, sand and water, with the smallest content of radioactive elements [2,3]. They are characterized by very high compressive strength, standard products are manufactured in a class of 15-20 MPa. Because of their considerable weight they are characterized by high acoustic insulation. Due to strong alkaline reaction they are resistant to biological corrosion in confined spaces. Thanks to the ability of heat accumulation they have very good thermal properties [4]. Additionally

\footnotetext{
${ }^{a}$ Corresponding author: komisarczyk.kasia@gmail.com
}

they are completely recyclable. White bricks are therefore materials that meet the requirements for modern construction.

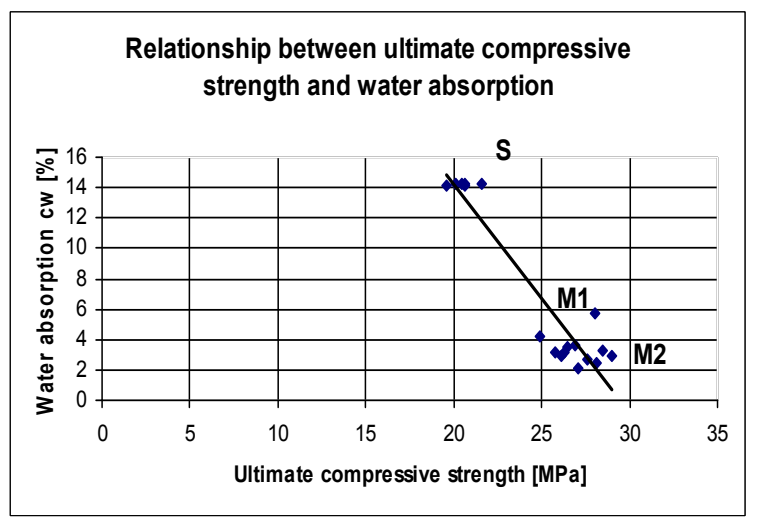

Figure 1 Relationship between ultimate compressive strength of sand-lime products and their water absorption. [4]

Because silicate products are compatible with sustainable development, all modifications, including the selection of additives introduced to the sand-lime mixture must also meet certain criteria. Interference in the basic composition of products through the use of various types of fillers has an impact on the internal structure as a consequence of changing the physical and mechanical properties. Changing parameters such as porosity and tightness will directly 
affect the compressive strength, sound insulation and frost resistance, but the ability of the material to resist the penetration of water.

White brick is a material which absorbs about $8 \%$ of $\mathrm{H} 2 \mathrm{O}$ less than the other wall products for construction of interior and exterior walls of buildings. According to research performed by A. Stępien, use of an basalt additive with a grain size of 2-4 mm leads to a significant improvement in strength of the product and to reduce its absorbency. The compressive strength of the modified product increased to almost $40 \mathrm{MPa}$, and the absorption capacity was reduced by about $50 \%$. The use of barite of the grain size of $0-2 \mathrm{~mm}$ increased the absorption by $40 \%$, the compressive strength increased to a similar level. (Fig.1) The addition of liquid admixture - lithium silicate resulted in doubling of the compressive strength and reduction in water absorption by about $20 \%$. [5,6] However, modification of white brick not always results in the improvement of their parameters. The article present the impact of admixture in the form of lithium water glass with different molar ratio on the properties of final silicate products.

\section{Examination of sand-lime products}

The main aim of my research is to determine the effect of modification of sand-lime products on their physical properties. Samples have been performed inncollaboration with the Silicate Production Plant in Ludynia following 4 stages of the production process. A mixture of quicklime and quartz sand was placed in reactors for 4-6 $\mathrm{h}$, where under the conditions of elevated temperature by the hydration process of $\mathrm{CaO}$ and $\mathrm{MgO}$, and the curing process, the lime slaking process took place. The mass of moisture content of 4-5\% (Fig.2) was subjected to hydraulic pressing (approx. $20 \mathrm{MPa}$ ) and then transported to an autoclave. During the autoclaving process, with the steam pressure of 16 bar and a small energy distribution at $203{ }^{\circ} \mathrm{C}$, the silicates were cured. After 6 hours of hardening the sample were prepared for the last stage of their formation- cooling.

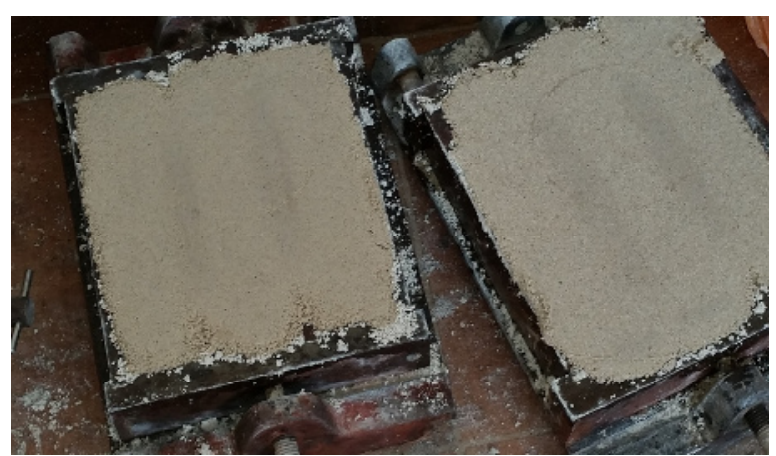

Figure 2 Compacted samples. Prepered for autoclaving process.

The experiment was conducted on the samples with dimensions of $40 \times 40 \times 160 \mathrm{~mm}$ (Fig. 3) I have prepared three sets of three samples each. To constant weight of the dry ingredients I added a slightly-turbid, lithium water glass having a molar ratio of 2.6 and 7.0. Admixture, which includes lithium hydroxide (1,0-5,0\%), colloidal silica- $\mathrm{SiO} 2(10,0-25,0 \%)$ and water $(50,0-$ $75,0 \%$ ), I added in the amount of $5 \%$ by weight of the total mixture.

Table 1 The content of ingrediens in the test samples.

\begin{tabular}{|c|c|c|c|}
\hline & Sand + Lime $[\mathrm{g}]$ & Water $[\mathrm{g}]$ & Admixture $[\mathrm{g}]$ \\
\hline $\mathrm{N}$ & 1800 & 90 & - \\
\hline $\mathrm{A}(7,0)$ & 1800 & - & 90 \\
\hline $\mathrm{B}(2,6)$ & 1800 & - & 90 \\
\hline
\end{tabular}

After 21 days after preparation of the samples, the products were subjected to the study of compressive strength, water absorption due to capillary action and absorption (by complete immersion in water). The samples were marked with letters: N, A and B. The sample marked with the letter $\mathrm{N}$ is the traditional sand-lime product, A-modified with water lithium glass with molar ratio of 7.0 and sample B - modified with water lithium glass having a molar ratio of 2.6. (Tab. 1)

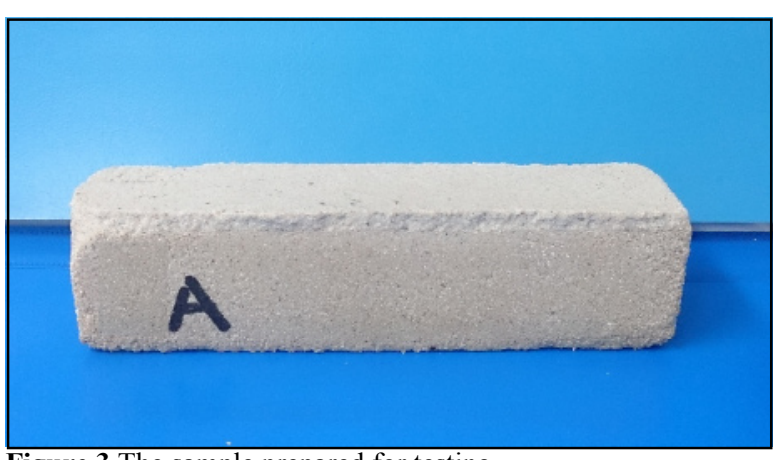

Figure 3 The sample prepared for testing.

\section{Research analysis}

\subsection{Capillary test}

The amount of capillary action is inversely proportional to the contact angle (liquid type), and the capillary diameter (pore size). Fig. 4 shows that the addition to the silicate mass lithium water glass having a mole ratio of 2.6 resulted in the greatest increase in the high of capillary action. (Fig. 5) Reduction of the diameter of the pores present in the product was noted. This was confirmed by the results of Mercury Intrusion Porosimetry. The use of porosimeter allows to determine the pore diameter in the range of $0,003-400 \mu \mathrm{m}$. According to the IUPAC classification in this range we have mesopores $(2<\mathrm{d}<50 \mathrm{~nm})$ and macropores $(\mathrm{d}>50 \mathrm{~nm})$, and the micropores $(\mathrm{d}<2 \mathrm{~nm})$ were not included in the measurement. In the sample A mesopores constitute $43 \%$ of all pores, which is above $20 \%$ more in comparison to the normalized sample. 


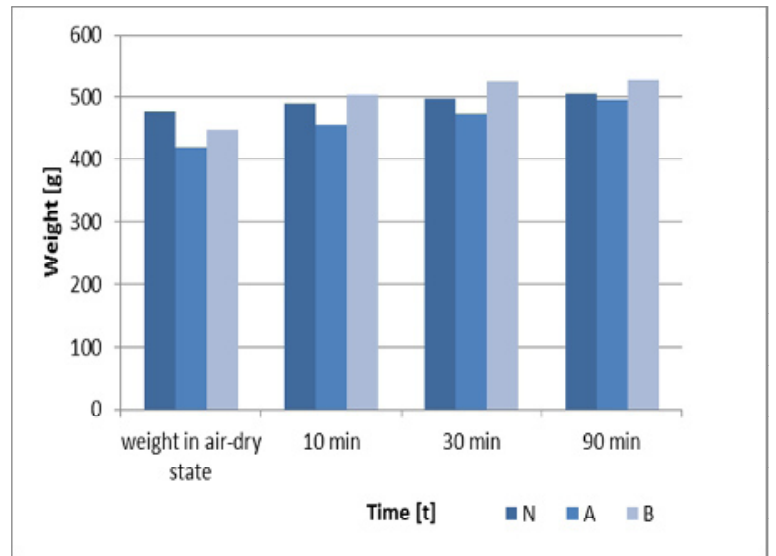

Figure 4 The results of capillary action of sample N, A and B.

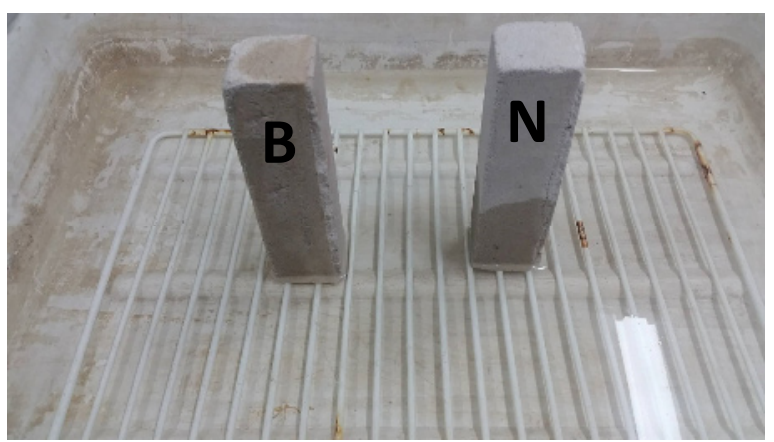

Figure 5 Capillary action of samples N and B.

\subsection{Compressive strength}

The research on the lime-sand products shows that the use of lithium silicate admixture have a negative impact on one of the main mechanical properties compressive strength. Fig. 6 shows the results of the measurements. In the sample $\mathrm{A}$ reduction in the strength to $3.2 \mathrm{MPa}$ was observed. In the sample $\mathrm{B}$ - to $5.9 \mathrm{MPa}$, which is three times less than the strength of the standard sample (17.29 MPa).

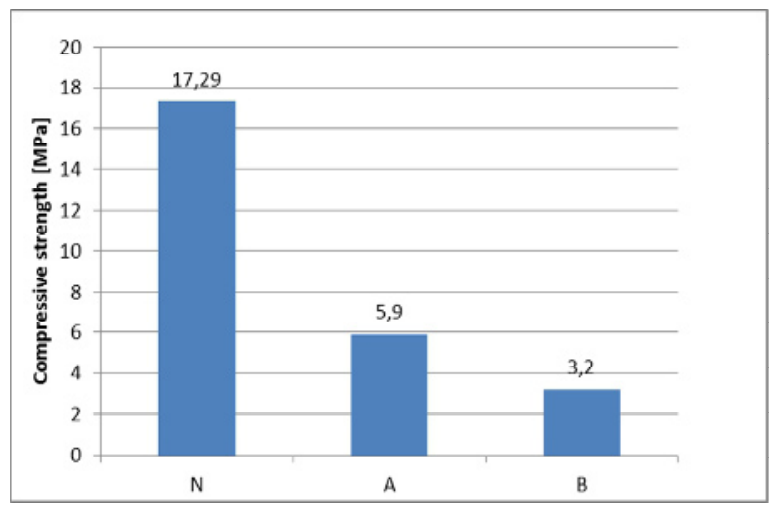

Figure 6 The results of compressive strenght of samples $\mathrm{N}, \mathrm{A}$ and $\mathrm{B}$.

\subsection{Water absorption}

Compressive strength is inversely proportional to absorption. The smaller the resistance, the greater the absorption.

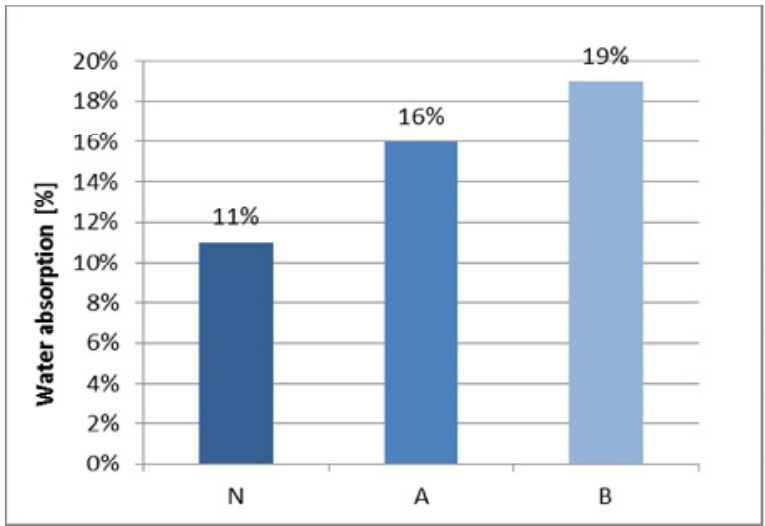

Figure 7 The results of water absorption of samples N, A, B.

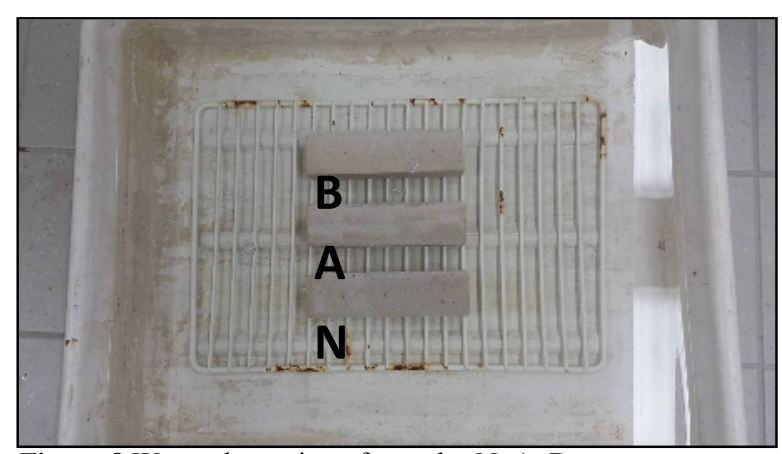

Figure 8 Water absorption of samples N, A, B.

Figure 7 shows that sample A increased the absorbency of a $5 \%$, sample $\mathrm{B}$, in turn, $8 \%$ with respect to a standard (11\%). The results therefore indicate that the use of lithium water glass admixture of different molar ratio changes the pore structure. (Fig 8) Changing the shape of the pores from the spherical to flattened influences the change in frost resistance.

\section{Conclusion}

Controlling of dosing of admixtures and additives can change the ability of silicate material to resist the penetration of water.

The choice of additives and admixtures does not always improve the performance of the resulting product. Lithium water glass reduces the strength of the products, increases water absorption and the amount of capillary.

The value of the molar ratio of lithium water glass is inversely proportional to the compressive strength, water absorption and capillary action.

Lithium water glass affects the pore structure. Changes the shape of the pores (pores flattened) and increases the number of pores having a diameter of $2-50 \mathrm{~nm}$.

\section{References}

1. Ustawa z 27 marca 2003 r. o planowaniu i zagospodarowaniu przestrzennym.

2. P. Parker Lilly E. World Outlook for All Silica. Brick and Shapes Excluding SemiSilica. The 2006- 
2011, Insead (Singapore and Fontainebleau, France 2005)

3. PN-EN 772-10. Określenie wilgotności elementów silikatowych i elementów $\mathrm{z}$ autoklawizowanego betonu komórkowego.

4. A. Stępień, R. Dachowski Structural modification of sand -lime blocks regarding their physical and mechanical features. 8th PhD Symposium in Kgs. Lyngby. (Denmark, 2010)

5. A. Stępień, R. Dachowski. The impact of various additives on the microstructure of silicate products. International Conference on Green Buildings and Sustainable Cities. (2011)

6. A Stępień, The impact of barium sulfate on the microstructural and mechanical properties of autoclaved silicate products. The $9^{\text {th }}$ International Conference "Environmental Engineering. (Vilnius, Lithuania, 2014) 